\title{
IMPLEMENTASI METODE ANALYTICAL HIERARCHY PROCESS (AHP) PADA SISTEM PENDUKUNG KEPUTUSAN PEMBELIAN MOBIL DI BANDAR LAMPUNG
}

\author{
${ }^{1}$ Admi Syarif, ${ }^{1}$ Ari Ardianto, ${ }^{1}$ Bambang Hermanto dan Machudor Yusman \\ 1Jurusan Ilmu Komputer, FMIPA, Universitas Lampung \\ Jl. Sumantri Brodjonegoro No. 1, Bandar Lampung, 35145 \\ 1admi.syarif@fmipa.unila.ac.id
}

\begin{abstract}
Car is an important transportation to support many activities in our daily life. There have been many variations of car based on models, price, specifications and so on. This study aims to implement the web-based Analytical Hierarchy Process (AHP) to recommend a car based on some criteria. The decision is done based on the following criteria as price, brand, cylinder capacity, fuel consumption, and passenger capacity. We used the data of 254 model variants car from six famous brands (Toyota, Daihatsu, Mitsubishi, Honda, Suzuki, and Nissan). The experiments have been to see the effectivity of the proposed method by giving different weight priority value. The results show that the method work well to give recommendation that suits consumers' desires.
\end{abstract}

Keywords: Analytical Hierarchy Process, Car, Decision Support System, MCDM.

\begin{abstract}
Abstrak
Mobil merupakan alat transportasi yang penting saat ini guna menunjang aktivitas maupun untuk memenuhi gaya hidup seseorang. Ada beragam jenis mobil dengan model, merk dan spesifikasi tehnis lainnya. Penelitian ini bertujuan mengimplementasikan metode AHP berbasis web untuk membantu merekomendasikan mobil yang sesuai dengan keinginan konsumen. Rekomendasi keputusan berbasisi 6 (enam) kriteria diantaranya harga, merk, kapasitas silinder, konsumsi BBM, dan kapasitas penumpang. Eksperimen dilakukan dengan menggunakan data 254 varian model mobil dengan enam merk terkenal Toyota, Daihatsu, Mitsubishi, Honda, Suzuki, dan Nissan). Hasil pengujian sistem telah bekerja dengan sangat baik. Pembobotan kriteria dan pemilihan alternatif sangat berpengaruh terhadap rekomendasi keputusan.
\end{abstract}

Kata kunci: Analytical Hierarchy Process, Mobil, Sistem Pendukung Keputusan, MCDM. 


\section{PENDAHULUAN}

Kota Bandar Lampung merupakan ibukota Provinsi Lampung yang secara

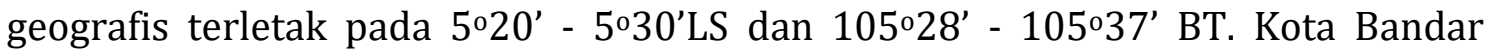
Lampung mempunyai luas wilayah $197,22 \mathrm{Km}^{2}$. Sebagai gerbang Sumatera dan juga pusat perekonomian di Provinsi Lampung, kota Bandar Lampung mengalami laju pertumbuhan penduduk yang tinggi, 1.71 persen per tahunnya [1]. Sebagai salah satu dampak pertumbuhan penduduk yang terus meningkat, kebutuhan alat transportasi, termasuk mobil, di Bandar Lampung meningkat. Berbagai harga, spesifikasi tehnis dan jenis mobil ditawarkan oleh produsen-produsen merk mobil terkenal. Keberagaman variasi ini mobil sering kali membuat konsumen kesulitan dalam mengambil keputusan untuk pembelian mobil khususnya mobil baru. Beberapa parameter yang biasanya menjadi pertimbangan konsumen dalam pembelian mobil adalah harga, merek, kapasitas silinder, konsumsi BBM dan kapasitas penumpang.

Teknologi komputer dalam beberapa dekade ini telah menunjukkan perkembangan yang signifikan. Komputer telah menjadi peralatan penting untuk pengolahan data dan pengambilan keputusan. Salah satu yang sangat dominan saat ini adalah kebutuhan informasi yang cepat dan akurat. dengan Sistem Pendukung Keputusan (SPK). SPK bertujuan menyediakan informasi, memberikan prediksi, serta memberikan solusi kepada pengguna agar dapat mengambil keputusan yang lebih baik. Beberapa metode SPK yang sangat dikenal yaitu Analytical Hierarchy Process (AHP) [2], Simple Additive Weighting (SAW), Weighted Product (WP) dan lain-lain.

AHP merupakan metode yang sering digunakan untuk menyelesaikan masalah yang kompleks dan memerlukan analisis yang mendalam. AHP pertama kali diperkenalkan oleh Thomas L. Saaty pada tahun 1976 [3]. Pada saat itu, AHP digunakan sebagai pendukung keputusan pembangunan pembangkit listrik dengan kriteria perekonomian nasional, dampak terhadap lingkungan, dan faktor politik, sedangkan alternatif keputusan terdiri dari pembangkit listrik skala kecil, pembangkit listrik tenaga batu bara, dan pembangkit listrik tenaga nuklir. Prinsip utama penyelesaian masalah pada metode ini dengan cara menyusun kerangka pemikiran dalam bentuk hierarki fungsional serta pemberian prioritas pada alternatif dan kriteria berdasarkan persepsi manusia [4]. Salah satu manfaat metode ini adalah mempermudah proses pengambilan keputusan dengan menguraikan proses keputusan kompleks menjadi keputusan-keputusan kecil. Selain itu, AHP juga memberikan fleksibilitas penilaian yang bersifat subjektif dan memvalidasinya dengan cara uji konsistensi penilaian [5].

Dalam beberapa dekade terakhir, AHP telah diimplementasikan pada berbagai bidang diantaranya di bidang kesehatan, bisnis, pendidikan dan lin-lain. Nurjamiah melaporkan implementasi AHP untuk mendeteksi pasien penyakit ginjal dengan kriteria proteinuira, hipertensi, kadar gula, dan GFR [6]. Pada bidang bisnis diantaranya R. Alamoundi [7] dan Eylem Koc [8]. Eylem Koc memanfaatkan AHP untuk pemilihan lokasi terbaik untuk pendirian gedung. Kriteria utama terdiri dari faktor sektoral, faktor lingkungan, biaya investasi, potensi tenaga kerja, dan potensi daerah [8]. Pada bidang pendidikan, Ellya Sestri mengimplementasi AHP untuk 
pemilihan dosen terbaik berdasarkan enam kriteria, yaitu: pengajaran, penelitian, pengabdian masyarakat, aktivitas internal, dan penilaian mahasiswa [8].

Penelitian ini bertujuan untuk mengimplementasikan metode AHP dalam sistem pendukung keputusan pembelian mobil di Bandar Lampung untuk memberikan solusi mobil terbaik berdasarkan preferensi kriteria yang diberikan oleh konsumen. Sistem dikembangkan berbasis Web dengan Bahasa pemrograman PHP. Sistem ini diharapkan dapat membantu calon pembeli mobil di Bandar Lampung dalam menentukan mobil yang akan dibeli. Objek penelitian ini meliputi tiga jenis mobil yaitu mobil jenis sedan, MPV dan juga SUV dengan 5 (lima) kriteria: harga mobil, merek, kapasitas silinder, konsumsi BBM dan kapasitas penumpang. Eksperimen dilakukan dengan menggunakan real data yang diperoleh dari berbagai dealer mobil yang ada di Bandar Lampung.

Paper ini terdiri dari 4 (empat) bagian. Bagian kedua adalah penjelasan tentang implementasi metode AHP yang akan digunakan pada penelitian ini. Bagian ketiga membahas eksperimen, analisis dan hasil yang diperoleh. Bagian akhir dari paper ini berisi simpulan.

\section{METODOLOGI PENELITIAN}

\subsection{IMPLEMENTASI METODE AHP}

Analytical Hierarchy Process (AHP) merupakan model pendukung keputusan yang menguraikan masalah yang kompleks menjadi kelompok yang lebih kecil serta menyusunnya ke dalam bentuk hierarki [10]. Implementasi metode AHP untuk mendapatkan rekomendasi keputusan biasanya dilakukan dengan beberapa tahapan berikut:

Tahap 1 : Identifikasi dan Penyusunan Hierarki Permasalahan

Tahapan ini merupakan proses identifikasi masalah serta penyusunan hierarki fungsional. Pada penelitian ini, terdapat 5 (lima) kriteria yang digunakan yaitu harga, merek, kapasitas silinder, konsumsi BBM, dan kapasitas penumpang.

Tahap 2 : Pembobotan Kriteria dan Penyusunan Matriks Perbandingan Berpasangan

Tahap ini merupakan tahap yang sangat mempengaruhi rekomendasi keputusan yang diperoleh. Pembobotan kriteria pada AHP menggunakan skala penilaian berpasangan dengan nilai antara 1 sampai 9 yang telah dipaparkan oleh Saaty [10]. Setelah dilakukan pembobotan setiap kriteria, selanjutnya menyusun matriks perbandingan berpasangan. Matriks perbandingan berpasangan matriks berukuran $n \times n$ dengan nilai elemennya nilai relatif antara kriteria ke-i terhadap kriteria ke-j. 
Tahap 3 : Normalisasi Matriks Perbandingan Berpasangan

Normalisasi matriks dilakukan untuk mendapatkan eigenvector suatu matriks. Normalisasi pada matriks dilakukan dengan cara pembagian elemen matriks dengan jumlah keseluruhan elemen pada kolom tersebut.

Tahap 4 : Menghitung Bobot Prioritas Kriteria

Bobot prioritas kriteria merupakan nilai rata-rata elemen matriks perbandingan ternormalisasi pada baris tersebut. Bobot prioritas kriteria didapat menggunakan persamaan 1.

$$
w_{i}=\frac{r_{i j}}{n}
$$

$w_{i}$ merupakan bobot prioritas kriteria ke-i, $r_{i j}$ merupakan elemen matriks perbandingan ternormalisas, dan $n$ merupakan jumlah kriteria.

Tahap 5 : Uji Konsistensi

Uji konsistensi dilakukan untuk mengetahui pembobotan yang dilakukan konsisten atau tidak. Uji konsistensi didasari dengan eigenvalue maksimum $\left(\lambda_{\max }\right)$. Proses perhitungan $\lambda_{\max }$ dengan cara perkalian matriks berpasangan $(A)$ dengan bobot prioritas kriteria $(w)$, maka didapatkan himpunan eigenvalue $(\lambda)$ berupa $\lambda_{1}, \lambda_{2}, \lambda_{3}, \lambda_{\ldots}, \lambda_{n}$. Selanjutnya $\lambda_{\text {max }}$ didapat dengan persamaan 2 .

$$
\lambda_{\max }=\sum \frac{\lambda}{n}
$$

Nilai $\lambda_{\text {max }}$ digunakan untuk menghitung nilai indeks konsistensi $(C I)$. Indeks konsistensi dapat dihitung dengan persamaan 3.

$$
C I=\frac{\lambda \max -n}{n-1}
$$

Selanjutnya menghitung rasio konsistensi $(C R)$. Apabila nilai rasio konsistensi kurang dari 0.1 maka pembobotan konsisten, apabila nilai rasio konsistensi 0.1 atau lebih maka pembobotan tidak konsisten dan hasil rekomendasi keputusan tidak valid dan perlu dilakukan pembobotan ulang. Perhitungan rasio konsistensi ditunjukkan pada persamaan 4 .

$$
C R=\frac{C I}{R I}
$$

Tahap 6 : Menghitung Bobot Prioritas Alternatif di Setiap Kriteria

Pada dasarnya tahapan ini merupakan perulangan tahapan 2 hingga 4 pada alternatif di setiap kriteria. Perulangan pada tahapan ini bergantung pada jumlah kriteria yang dipertimbangkan. Hasil perhitungan pada tahap ini berupa matriks keputusan $\left(S_{i j}\right)$. $i$ merupakan jumlah kriteria, sedangkan $j$ merupakan jumlah alternatif yang dipertimbangkan. 
Tahap 7 : Perankingan Alternatif

Tahap ini merupakan tahap akhir untuk mendapatkan rekomendasi keputusan. Perankingan alternatif ini dimulai dengan perhitungan prioritas global. Prioritas global didapat dengan cara mengalikan bobot prioritas alternatif dan bobot prioritas kriteria, selanjutnya hasil perkalian tersebut ditotal berdasarkan alternatifnya. Secara matematis perhitungan prioritas global ditunjukkan pada persamaan 5 .

$$
S_{i}=\sum\left(S_{i j}\right)\left(w_{i}\right)
$$

Prioritas global yang didapat kemudian diurutkan dari nilai terbesar hingga terkecil. Alternatif yang menjadi rekomendasi keputusan adalah alternatif dengan prioritas global terbesar.

\subsection{PERANCANGAN SISTEM}

Perancangan Sistem Pendukung Keputusan Pembelian Mobil ini digambarkan dalam bentuk diagram Unified Modelling Language (UML) yang terdiri dari diagram alur sistem, use case diagram, activity diagram, dan class diagram. Use Case Diagram digunakan untuk menggambarkan interaksi antara user dengan menu dan fitur-fitur yang terdapat dalam sistem. Activity diagram digunakan untuk memaparkan tahapan user untuk menggunakan fitur sistem secara lebih detail. Sedangkan class diagram untuk menggambarkan interaksi antar boundary, proses, hingga interaksi database. Diagram alur sistem terhadap pengguna ditunjukkan pada

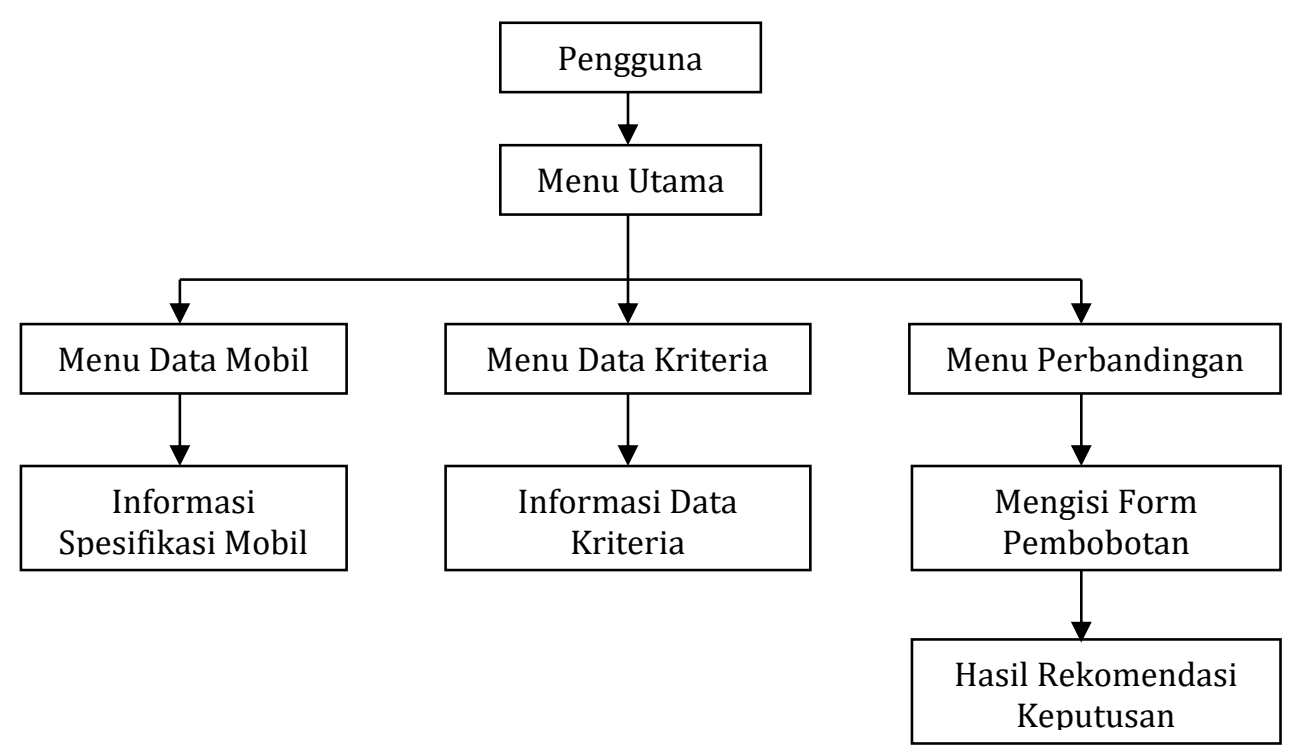

Gambar 1. Perancangan Arsitektur SPK Pembelian Mobil

Terdapat beberapa tahapan yang harus dilakukan pengunjung untuk memperoleh rekomendasi mobil. Pengguna yang ingin membandingkan mobil 
terlebih dahulu mengakses menu perbandingan. Beberapa form yang harus diisi diantaranya form bobot kriteria, preferensi merek, dan pemilihan alternatif. Selanjutnya sistem memproses perhitungan AHP dan menampilkan hasil rekomendasi keputusan.

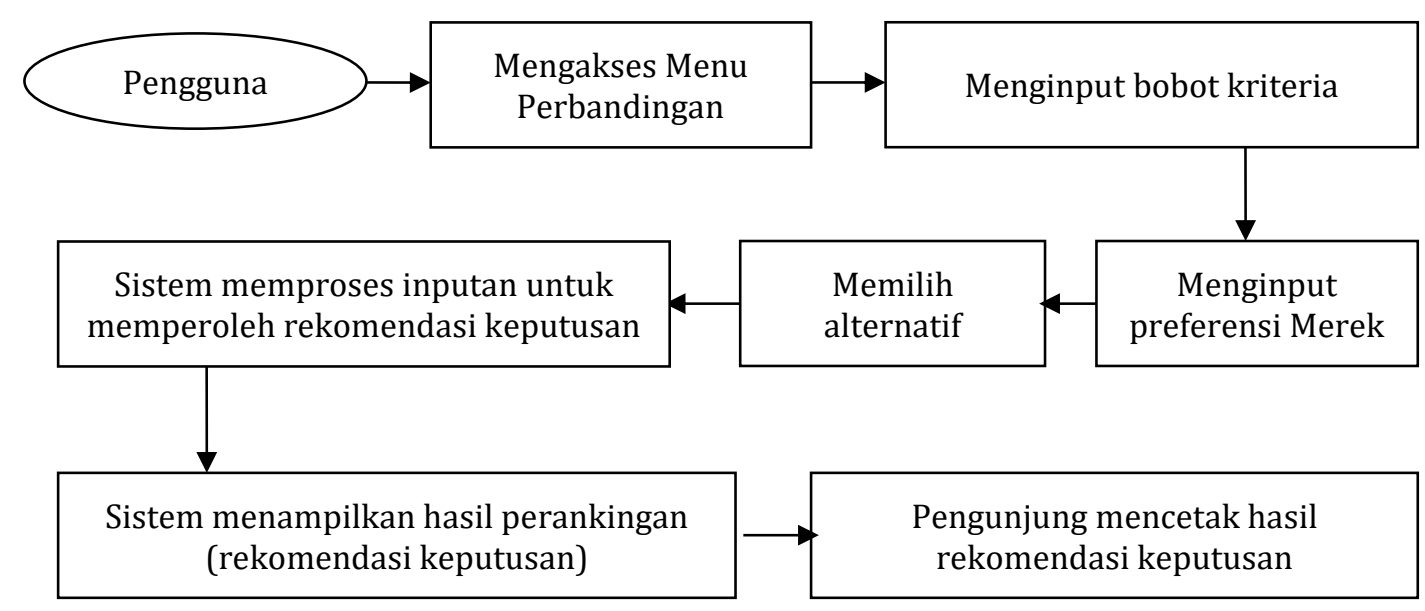

Gambar 2. Tahapan perbandingan mobil pada sistem

\section{HASIL DAN PEMBAHASAN}

\subsection{Pengumpulan Data}

Proses pengumpulan data dilakukan dengan cara mengambil data mobil yang dijual di beberapa dealer mobil yang ada di Bandar Lampung. Selain itu studi literatur digunakan untuk melengkapi data mobil yang diperlukan dengan cara mengunjungi situs web yang menyediakan informasi otomotif yaitu Gabungan Industri Kendaraan Bermotor Indonesia (GAIKINDO) [9]. Data yang diperoleh berupa mobil jenis SUV, MPV dan sedan yang telah dipasarkan di Indonesia khususnya di Bandar Lampung. Pada proses pengumpulan data mobil ini diperoleh data harga, merek, kapasitas silinder, konsumsi BBM, dan kapasitas penumpang sebagai data primer yang digunakan pada saat proses perhitungan AHP. Selain itu diperoleh data jumlah silinder, jenis bahan bakar, jenis transmisi, tenaga, torsi dan fitur keselamatan (airbag) sebagai data tambahan untuk memberikan informasi spesifikasi mobil kepada pengunjung. Data terdiri dari enam merek mobil dengan total 254 varian. Merk mobil yang digunakan terdiri dari enam merek mobil yaitu Toyota, Daihatsu, Mitsubishi, Honda, Suzuki, dan Nissan.

\subsection{Hasil Penelitian}

Sistem diimplementasikan berbasis web menggunakan bahasa pemrograman PHP dengan framework laravel, Database Mysql, dan dijalankan pada PC Acer Aspire E14 E5-473G-73FJ. Sistem ini merupakan sistem informasi untuk membantu pengambilan keputusan khususnya pembelian mobil baru di Bandar Lampung. Metode Analytical Hierarchy Process (AHP) diimplementasikan pada sistem untuk 
menentukan rekomendasi mobil berdasarkan bobot kriteria dan pemilihan alternatif oleh pengunjung. Sistem ini juga menyediakan informasi data mobil dan juga data dealer yang terdapat di Bandar Lampung. Untuk melihat spesifikasi mobil pengunjung dapat mengakses menu data mobil. Tampilan menu data mobil ditunjukkan pada Gambar 3.

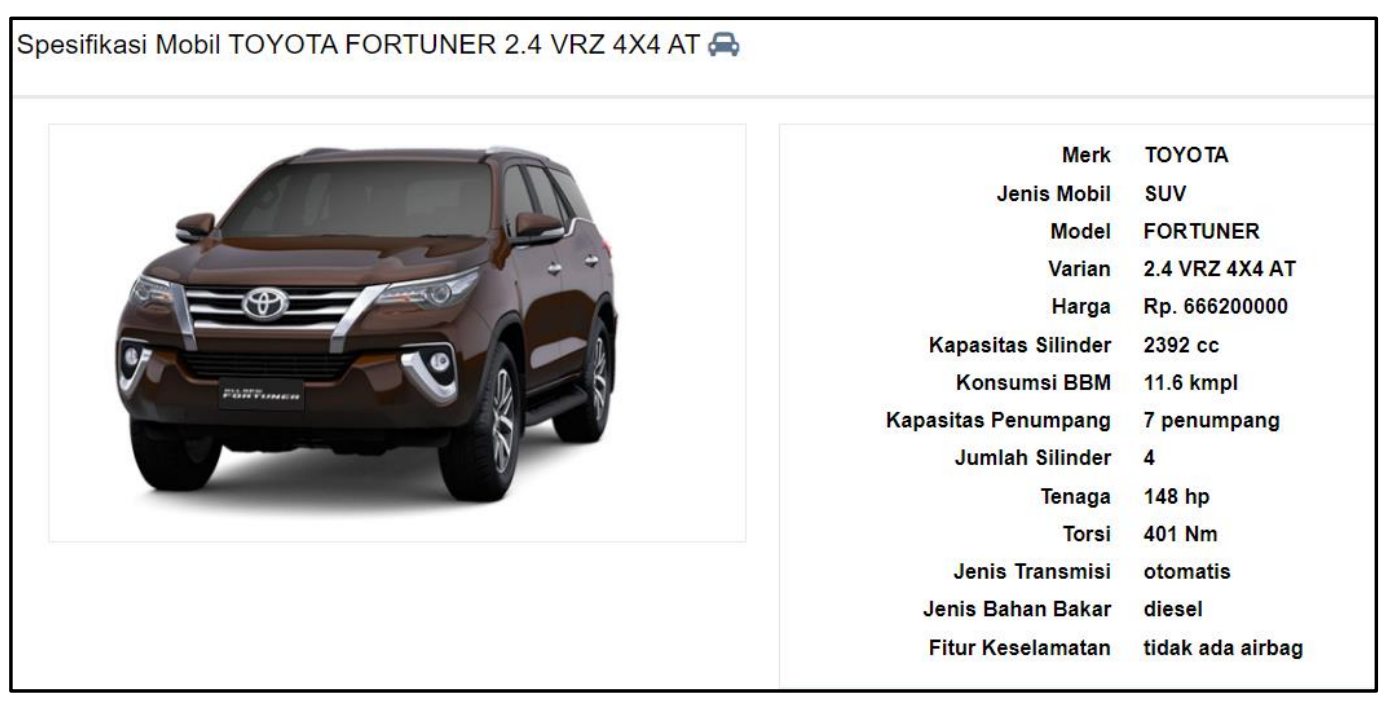

Gambar 3. Halaman Data Mobil.

Perbandingan mobil dapat dilakukan pengguna dengan cara mengakses menu perbandingan serta mengisi form pada halaman tersebut. Form yang harus diisi yaitu form bobot kriteria dan preferensi merek seperti yang ditunjukkan Gambar 4a. Inputan yang valid berupa nilai numerik antara 1 sampai 9. Selanjutnya pengguna memilih mobil yang ingin dibandingkan seperti pada Gambar 4b. Pengguna dapat melihat hasil perbandingan dengan cara menekan button Bandingkan.

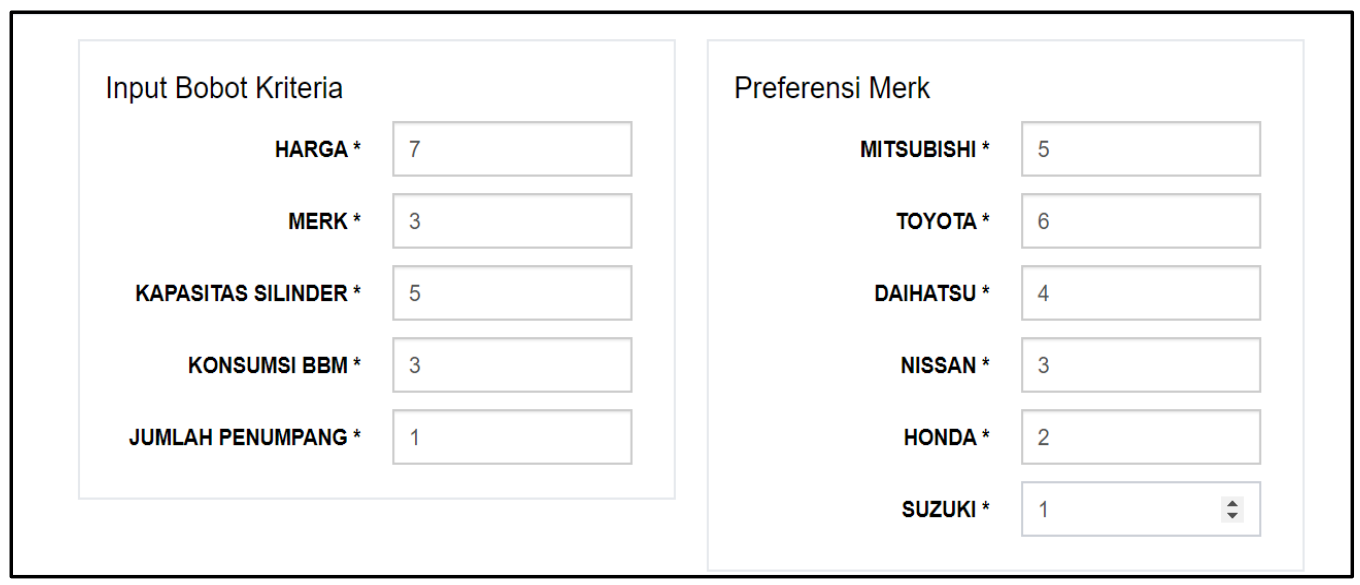

(a) Form Pembobotan kriteria dan preferensi merk 


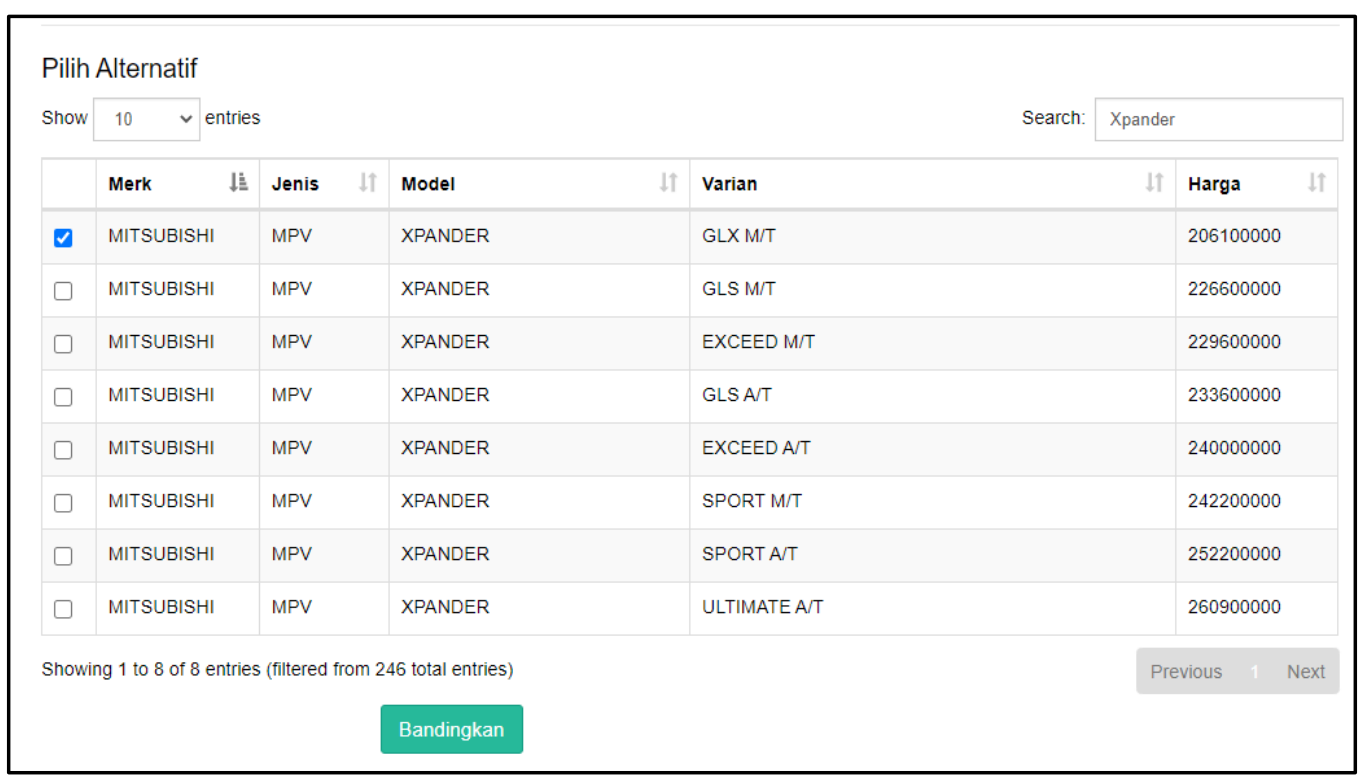

(b) Form Pemilihan Alternatif

Gambar 4. Halaman Pembobotan

Pada halaman ranking menampilkan informasi hasil proses AHP berupa bobot prioritas kriteria, hasil uji konsistensi seperti yang ditunjukkan pada Gambar 5a. Pada halaman ini juga menampilkan hasil rekomendasi keputusan berupa urutan mobil dengan bobot prioritas tertinggi hingga terendah seperti Gambar 5b. Pengguna dapat menyimpan hasil perbandingan dengan cara menekan button Cetak PDF.

\begin{tabular}{|c|c|c|c|}
\hline \multicolumn{2}{|c|}{ Bobot Prioritas Kriteria } & \multicolumn{2}{|l|}{ Preferensi Merk } \\
\hline Harga : & 0.36842 & MITSUBISHI * & 5 \\
\hline Merk: & 0.15789 & TOYOTA * & 6 \\
\hline Kapasitas Silinder : & 0.26316 & DAlHATSU * & 4 \\
\hline KonsumsiBBM : & 0.15789 & NISSAN * & 3 \\
\hline KapasitasPenumpang : & 0.05263 & HONDA* & 2 \\
\hline Konsistensi : & Konsisten & suzukl* * & 1 \\
\hline
\end{tabular}

(a) Hasil bobot prioritas kriteria 


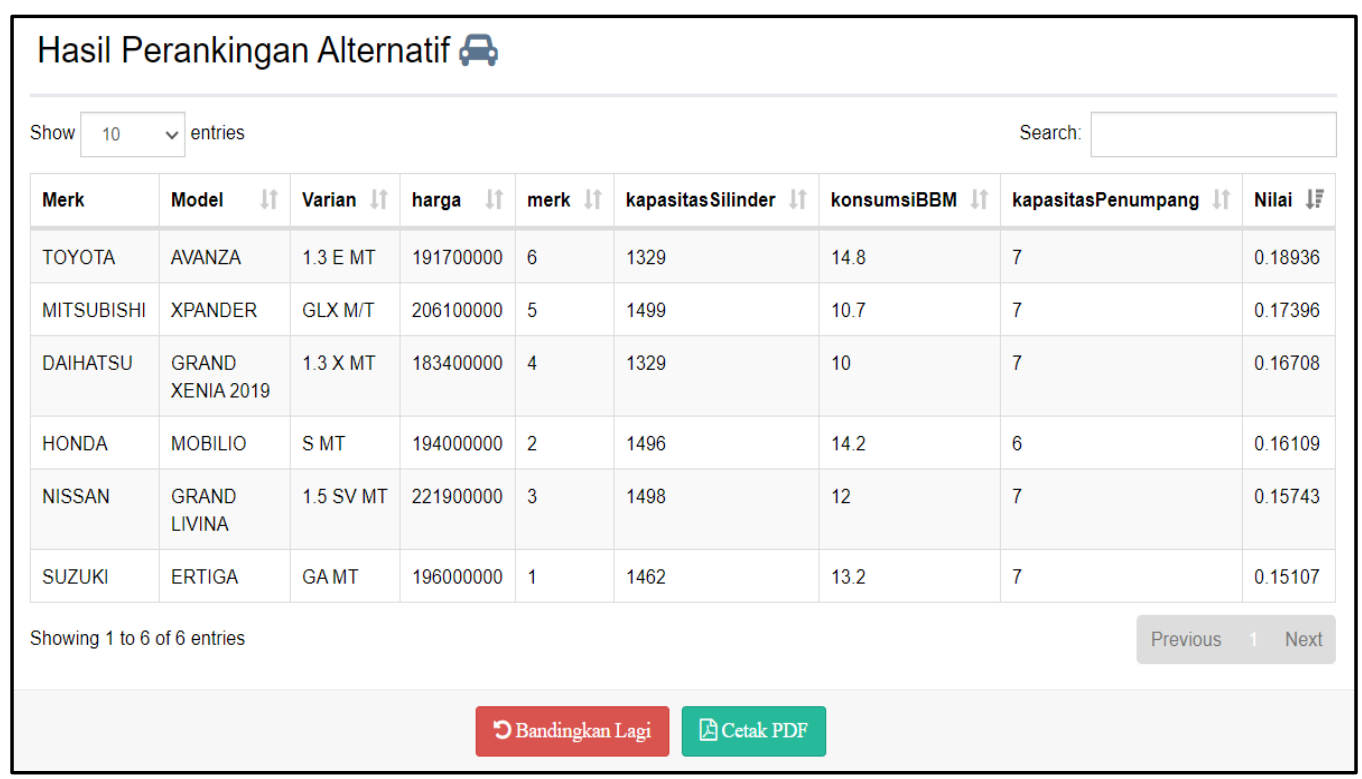

(b) Hasil rekomendasi keputusan

Gambar 5. Halaman Ranking

Pengujian sistem dilakukan menggunakan black box testing metode equivalent partitioning. Terdapat 20 test case untuk menguji fungsi input dan output pada sistem. Pengujian difokuskan pada form pembobotan kriteria, preferensi merek, pemilihan alternatif hingga output dari proses AHP pada halaman ranking. Hasil pengujian yang diperoleh menunjukkan bahwa fungsi input dan output sistem telah sesuai yang diharapkan.

Untuk mengetahui performa sistem yang dikembangkan dilakukan, kami melakukan beberapa eksperimen dengan menggunakan 6 (enam) alternatif merek mobil yang berbeda dengan jenis MPV yaitu: Mitsubishi Xpander GLX MT (A1), Toyota Avanza 1.3 E MT (A2), Daihatsu Xenia 1.3 X MT (A3), Honda Mobilio S MT (A4), Suzuki Ertiga GA MT (A5), dan Nissan Grand Livina 1.5 SV MT (A6). Masingmasing merk menggunakan nilai preferensi yang sama yaitu Toyota (6), Mitsubishi (5), Daihatsu (4), Nissan (3), Honda (2), dan Suzuki (1).

Eksperimen dilakukan dengan memberikan bobot kriteria yang berbedabeda untuk setiap kriteria. Kriteria yang digunakan pada penelitian ini yaitu Harga (C1), Merek (C2), Kapasitas Silinder (C3), Konsumsi BBM (C4), Kapasitas Penumpang (C5). Pada Tabel 1 ditunjukkan hasil eksperimen yang diperoleh. Hasil ini menunjukkan bahwa sistem ini sangat sensitif terhadap nilai bobot kriteria yang diberikan. Perubahan nilai kriteria secara langsung akan mempengaruhi ranking untuk alternatif kendaraan yang dipilih. 
Tabel 1. Hasil eksperimen pada sistem

\begin{tabular}{cccccccccccc}
\hline \multirow{2}{*}{ Eksperimen } & \multicolumn{4}{c}{ Nilai Bobot Kriteria } & \multicolumn{4}{c}{ Hasil perankingan } \\
& C1 & C2 & C3 & C4 & C5 & A1 & A2 & A3 & A4 & A5 & A6 \\
\hline 1 & 9 & 7 & 5 & 3 & 1 & 5 & 2 & 4 & $\mathbf{1}$ & 3 & 6 \\
2 & 9 & 5 & 7 & 3 & 1 & 5 & 3 & 4 & $\mathbf{1}$ & 2 & 6 \\
3 & 7 & 3 & 1 & 9 & 5 & 6 & $\mathbf{1}$ & 5 & 2 & 3 & 4 \\
4 & 7 & 5 & 1 & 9 & 3 & 6 & $\mathbf{1}$ & 5 & 2 & 3 & 4 \\
5 & 3 & 9 & 1 & 7 & 5 & 5 & $\mathbf{1}$ & 6 & 3 & 2 & 4 \\
6 & 3 & 1 & 9 & 7 & 5 & 5 & $\mathbf{1}$ & 6 & 2 & 3 & 4 \\
7 & 5 & 1 & 9 & 3 & 7 & 4 & 2 & 6 & 3 & $\mathbf{1}$ & 5 \\
8 & 5 & 3 & 9 & 1 & 7 & 2 & 4 & 6 & 5 & $\mathbf{1}$ & 3 \\
9 & 1 & 9 & 7 & 5 & 3 & 5 & 2 & 6 & $\mathbf{1}$ & 3 & 4 \\
10 & 1 & 9 & 5 & 7 & 3 & 5 & $\mathbf{1}$ & 6 & 2 & 3 & 4 \\
\hline
\end{tabular}

Tabel di atas menunjukkan rekomendasi keputusan bervariasi. Rekomendasi prioritas utama pada Toyota Avanza muncul 5 kali, Honda Mobilio 3 kali, Suzuki Ertiga 2 kali. Hal tersebut menunjukkan bahwa pembobotan kriteria dan alternatif yang dipilih sangat berpengaruh terhadap rekomendasi keputusan yang dihasilkan, sehingga diperlukan pemahaman dan pertimbangan dalam pembobotan kriteria dan pemilihan alternatif agar mendapatkan rekomendasi keputusan sesuai yang diharapkan.

\section{SIMPULAN}

Paper ini membahas implementasi AHP sebagai sistem pendukung keputusan pembelian mobil baru di Kota Bandar Lampung. Sistem dikembangkan berbasis web dengan bahasa pemrograman PHP. Eksperimen dilakukan dengan menggunakan data real yang diambil dari berbagai dealer mobil yang ada di kota Bandar Lampung (254 data kendaraan dengan 6 merek). Penelitian ini menggunakan 5 (lima) kriteria yaitu harga, merek, kapasitas silinder, konsumsi BBM, dan kapasitas penumpang. Nilai kriteria diberikan bervariasi sesuai dengan persepsi. Hasil eksperimen menunjukkan bahwa sistem ini sangat efektif dan sensitif terhadap nilai parameter.

\section{UCAPAN TERIMA KASIH}

Terima kasih kepada Ketua Gabungan Industri Kendaraan Bermotor Indonesia (GAIKINDO) yang telah memberikan data-data pada penelitian ini.

\section{DAFTAR PUSTAKA}

[1] Badan Pusat Statistik Kota Bandar Lampung, Kota Bandar Lampung Dalam Angka 2017, Bandar Lampung: BPS Kota Bandar Lampung, 2017. 
[2] M. Balubaid and R. Alamoundi, "Application of the Analytical Hierarchy Process (AHP) to Multi-Criteria Analysis for Contractor Selection," American Journal of Industrial and Bussiness Management, vol. 5, pp. 581-589, 2015.

[3] F. Sari, Metode Dalam Pengambilan Keputusan, Yogyakarta: CV Budi Utama, 2018.

[4] S. Setiawan, "Sistem Pendukung Keputusan Pemilihan Kendaraan Dinas Menggunakan Analytical Hierarchy Process," Bina Insani ICT Journal, vol. 3, pp. 122-135, 2016.

[5] A. Harjanto, "Sistem Pendukung Keputusan Seleksi Calon Karyawan Berdasarkan Hasil Tes Psikologi Kepribadian Menggunakan Metode AHP," Jurnal Informatika, vol. 14, pp. 50-60, 2014.

[6] Nurjamiyah, "Sistem Pendukung Keputusan Metode AHP dalam Penentuan Seseorang Beresiko Terkena Penyakit Ginjal," Jurnal Komputer Terapan Vol.2, No.1, pp. 41-54, 2016.

[7] M. Damdinsuren and B. Ishdamba, "Application of the Analytical Hierarchy Process in Choosing Project Manager," International Journal of English Literature and Social Science, vol. 2, no. 4, pp. 155-160, 2017.

[8] E. Koc and H. A. Burhan, "An Application of Analytic Hierarchy Process (AHP) in a Real World Problem of Store Location Selection," Advances in Management \& Applied Economics, Vol. 5, No.1, pp. 41-50, 2015.

[9] GAIKINDO, "Gabungan Industri Kendaraan Bermotor Indonesia," April 2019. [Online]. Available: http://www.gaikindo.or.id. [Accessed 30 May 2019].

[10] R. W. Saaty, "The Analytic Hierarchy Process - What It Is and How It Is Used," Math! Modelling Vol. 9, No3-5, pp. 161-176, 1987. 